Pontifícia Universidade $C_{\text {atílica }}$

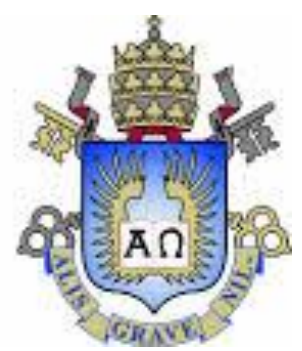

Nataly Netchaeva Mariz

\title{
A potencialidade narrativa do sintoma psicossomático
}

Tese apresentada ao Programa de PósGraduação em Psicologia Clínica da PUC-Rio como requisito parcial para a obtenção do título de Doutor em Psicologia Clínica

Orientadora: Prof (a) Silvia Maria Abu-Jamra Zornig 


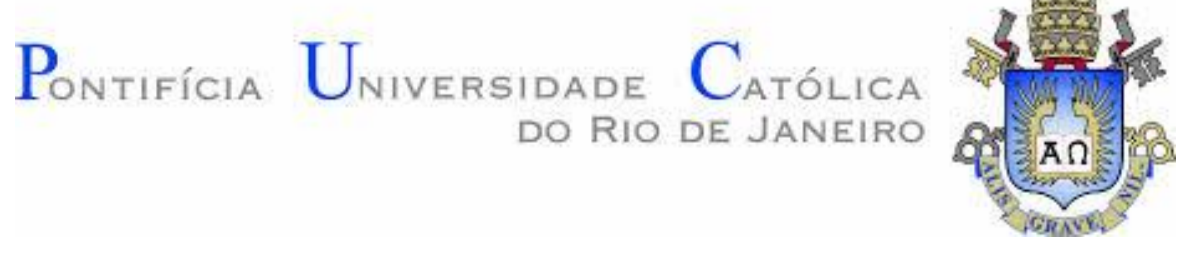

Nataly Netchaeva Mariz

\title{
A potencialidade narrativa do sintoma psicossomático
}

Tese apresentada como requisito parcial para obtenção do grau de Doutor pelo Programa de Pós-Graduação em Psicologia Clínica do Departamento de Psicologia do Centro de Teologia e Ciências Humanas da PUCRio. Aprovada pela Comissão Examinadora abaixo assinada.

\author{
Prof(a) Silvia Maria Abu-Jamra Zornig \\ Orientadora \\ Departamento de Psicologia -PUC-Rio \\ Prof(a) Maria Inês Garcia de Freitas Bittencourt \\ Departamento de Psicologia -PUC-Rio \\ Prof (a) Flavia Sollero de Campos \\ Departamento de Psicologia -PUC-Rio \\ Fernanda Pacheco Ferreira \\ PNPD Capes PPGTP/ UFRJ \\ Prof (a) Issa Leal Damous \\ Dept $^{\circ}$ de Psicologia - UFF/Rio das Ostras
}

Prof(a) Denise Berruezo Portinari

Coordenadora setorial de Pós-Graduação e Pesquisa do Centro de Teologia e Ciências Humanas - PUC-Rio

Rio de Janeiro, 20 de março de 2015 
Todos os direitos reservados. É proibida a reprodução total ou parcial do trabalho sem a autorização da autora, do orientador e da universidade

\section{Nataly Netchaeva Mariz}

Possui Graduação em Psicologia pela UFRJ (2004), especialização em Psicologia Clínica-Hospitalar HUPE/UERJ (2007), mestrado (2010) e doutorado (2015) em Psicologia Clínica pela PUC-Rio, tendo participado de doutoradosanduiche na Université René Descartes - Paris V (2006-2007).

Ficha Catalográfica

Netchaeva-Mariz, Nataly

O potencial narrativo do sintoma psicossomático / Nataly Netchaeva Mariz; orientadora: Silvia Maria Abu-Jamra Zornig. -2015

$151 \mathrm{f} ; 30 \mathrm{~cm}$

Tese (Doutorado em Psicologia) - Pontifícia Universidade Católica do Rio de Janeiro, Rio de Janeiro, 2015

Inclui bibliografia

1 Psicologia - Teses. 2. Corpo 3. Psicossomática 4. narratividade 5 . co-construção narrativa I. Zornig, Silvia Maria Abu-Jamra. II. Pontifícia Universidade Católica do Rio de Janeiro. Departamento de Psicologia. III. Título 


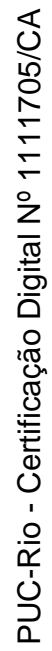

Para Nancy Cotia Mariz (in memoriam) 


\section{Agradecimentos}

À Silvia Zornig pela aposta, as oportunidades e a orientação

À banca examinadora que gentilmente aceitou participar desta defesa.

A Sylvain Missonnier e Bernard Golse pelo acolhimento na Paris V, dando-me oportunidade de conhecer a pesquisa francesa e assistir os seminários, o que me possibilitou entrar em contato com "outras linguagens".

Ao Franck Zigante por me acolher em seu grupo de trabalho e possibilitar uma troca sobre o tema da narratividade.

A CNPq pela bolsa de doutorado e CAPES pela bolsa sanduiche em Paris que tornaram possível a elaboração desta pesquisa.

A Roxane, Khaled, Veronique, Carla Cobra e Sabira por tornarem minha estadia em Paris mais enriquecedora.

Aos amigos da Maison du Brésil.

À Marcia Azevedo que, ao longo dos anos, me incentivou a ter uma existência mais criativa.

À Vanuza Campos Postigo, pelos anos de amizade e de trocas psicanalíticas.

Aos amigos e colegas de orientação: Sergio (in memoriam), Ana Carolina, Natalia Guimarães, Natalia Cidade, Helena e Fernanda.

Aos demais companheiros de doutorado.

Aos professores e funcionários da PUC. 
Aos supervisores clínicos que me acompanharam ao longo da minha formação, contribuindo ampliar minha escuta para além das palavras.

Aos meus pais Tatiana e Arnaldo que me possibilitaram o encontro com várias línguas e culturas.

Às minhas irmãs: Ana Sofia, Ligia, Nancy e Virginia. Cada uma, em sua singularidade, me ensina a ver a beleza na diferença.

Klaus pela compreensão durante os períodos que estive ausente.

Aos demais amigos, em especial Lucas que, como um irmão, sempre acompanhou minha trajetória. 


\section{Resumo}

Netchaeva-Mariz, Nataly; Zornig, Silvia Abu-Jamra (orientadora). A potencialidade narrativa do sintoma psicossmatico. Rio de Janeiro, 2015. 151p. Tese de Doutorado - Rio de Janeiro - Departamento de Psicologia, Pontifícia Universidade Católica do Rio de Janeiro.

Esta pesquisa teórico-clínica versa sobre uma potencialidade narrativa subjacente ao adoecimento psicossomático. Propomos que o fenômeno psicossomático remete a uma tentativa de comunicação precoce a ser "escutada", buscando oferecer uma alternativa à visão tradicional sobre o adoecimento psicossomático, entendido como uma falha dos processos de elaboração. Com intuito de enriquecer esta discussão, trazemos a noção de narratividade, compreendida como uma comunicação com outro que, na sua dimensão precoce, passa pela expressividade corporal. Baseamo-nos nos estudos sobre os primórdios da vida psíquica que nos indicam a centralidade do corpo nas primeiras formas de comunicação com mundo externo. Em termos de manejo clínico, podemos afirmar que, através do olhar atento de um outro, os sintomas corporais podem adquirir um valor narrativo por meio de uma co-construção de sentido. Desse modo, consideramos que o processo analítico é constituído de um encontro de duas subjetividades, a trabalho, em busca da construção de uma narrativa do sofrimento humano.

\section{Palavras-chave}

Corpo; psicossomática; narratividade; co-construção narrativa 


\section{Résumé}

Netchaeva-Mariz, Nataly; Zornig, Silvia Abu-Jamra (directrice). La potentialité narrative du symptome psychosomatique. Rio de Janeiro, 2015. 151p. Thèse de Doctorat - Rio de Janeiro - Departamento de Psicologia, Pontifícia Universidade Católica do Rio de Janeiro.

Cette recherche théorico-clinique soutient l'idée d'un potentiel narratif sous-jacent aux maladies psychosomatiques. L'hypothèse est que le phénomène psychosomatique renvoie à une tentative de communication précoce qui doit être « écoutée » et non prise pour un échec des processus d'élaboration, comme dans la vision traditionnelle de la maladie psychosomatique. Viendra enrichir cette discussion la notion de narrativité comprise comme une communication, ce qui dans sa dimension précoce implique l'expressivité corporelle. Nous nous appuyons sur des études du tout début de la vie psychique qui indiquent la centralité du corps dans les premières formes de communication avec le monde extérieur. En ce qui concerne le cadre analytique nous pouvons dire que c'est à travers le regard attentif de l'autre, dans une co-construction de sens, que les symptômes corporels peuvent acquérir une valeur narrative. Ainsi, nous considérons le processus d'analyse comme une rencontre entre deux subjectivités opérant à la recherche de la construction d'un récit de la souffrance humaine.

\section{Mots-clés}

Corps ; psychosomatique ; narrativité ; co-construction narrative 


\section{Sumário}

1. Introdução

2. Corpo: uma construção teórica em Freud

2.1. Os "primórdios" da psicanálise: as origens de uma visão sobre o corpo

20

2.2. Os três "tempos" do corpo em Freud 23

2.2.1. O corpo fragmentado: o prazer do órgão no autoerotismo 25

2.2.2. A unidade corporal narcísica 32

2.2.3. Dupla incidência do corpo: Eu corporal e transbordamento 41

2.3. A angustia: entre o corpo e o outro 47

3. O campo da psicossomática 55

3.1. Entre o biológico e o somático: um corpo para além do organismo

3.2. Psicossomática Psicanalítica 63

3.3. Transtornos psicossomáticos: uma questão de limites? 67

3.4. As origens precoces do sintoma somático 74

3.5. Adoecimento psicossomático: falhas de pensamento ou zonas de fragilidade?

4. Corpo nos primórdios: a origem da capacidade narrativa

4.1 Habitando o corpo

4.1.1. O corpo como morada

4.2. O corpo: espaço de encontro constitutivo

4.2.1. Um corpo "inabitado": onde o encontro não pôde ocorrer

5. Corpo e a co-construção narrativa na clínica contemporânea

5.1. A escuta psicanalítica: um movimento em três tempos

5.2. A "parte bebê de si": algumas reflexões sobre a dimensão arcaica na clínica com pacientes adultos

5.3. O corpo como comunicação precoce: uma narrativa a dois 
5.3.1. A pontencialidade narrativa do sintoma psicossomático

5.3.2. Por uma escuta ampliada do corpo: o analista como "narrador"

133

6. Conclusão

141

7. Referências Bibliográficas 
Um homem é sempre um narrador de histórias, vive rodeado por suas histórias e as histórias dos outros, vê tudo o que lhe acontece através delas; e procura viver sua vida como se a narrasse Jean-Paul Sartre 